Blanchard Helen (Orcid ID: 0000-0003-3372-5027)

\title{
Specificity and affinity of neuraminic acid exhibited by canine rotavirus strain K9 carbohydrate-binding domain (VP8*)
}

Rahul Mishra ${ }^{\mathrm{a}}$, Xing Yu ${ }^{\mathrm{a}}$, Chandan Kishor ${ }^{\mathrm{a}}$, Gavan Holloway ${ }^{\mathrm{b}}$, Kam Lau ${ }^{\mathrm{a}}$, Mark von Itzstein ${ }^{\mathrm{a}}$, Barbara. S. Coulson ${ }^{\mathrm{b}}$, and Helen Blanchard ${ }^{\mathrm{a} *}$

anstitute for Glycomics, Griffith University, Gold Coast Campus, Queensland 4222, Australia.

${ }^{\mathrm{b}}$ Department of Microbiology and Immunology, The University of Melbourne, at the Peter Doherty Institute for Infection and Immunity, Melbourne, Victoria 3000, Australia.

*Corresponding author: Professor Helen Blanchard, Institute for Glycomics, Griffith University, Gold Coast campus, Queensland 4222, Australia. Phone: +61 7555 27023, E-mail: h.blanchard@griffith.edu.au

Running Header: Rotavirus strain canine K9 carbohydrate specificity

Keywords: Rotavirus, canine K9 strain, carbohydrate-recognition

This is the author manuscript accepted for publication and has undergone full peer review but has not been through the copyediting, typesetting, pagination and proofreading process, which may lead to differences between this version and the Version of Record. Please cite this article as doi: $10.1002 / \mathrm{jmr} .2718$

This article is protected by copyright. All rights reserved. 


\begin{abstract}
The outer capsid spike protein VP4 of rotaviruses is a major determinant of infectivity and serotype specificity. Proteolytic cleavage of VP4 into two domains, VP8* and VP5*, enhances rotaviral infectivity. Interactions between the VP4 carbohydrate-binding domain (VP8*) and cell surface glycoconjugates facilitate initial virus-cell attachment and subsequent cell entry. Our STD NMR and ITC studies demonstrated that VP8* ${ }_{64-224}$ of canine rotavirus strain K9 interacts with $\mathrm{N}$-acetyl- and $\mathrm{N}$-glycolyl neuraminic acid derivatives, exhibiting comparable binding epitopes to VP8* from other neuraminidase-sensitive animal rotaviruses from pigs (CRW-8), cattle (NCDV), and Rhesus monkeys (RRV). Importantly, evidence was obtained for a preference by $\mathrm{K} 9$ rotavirus for the $N$-glycolyl- over the $N$-acetylneuraminic acid derivative. This indicates that a VP4 serotype 5A rotavirus (such as K9) can exhibit a neuraminic acid receptor preference that differs from that of a serotype 5B rotavirus (such as RRV), and the receptor preference of rotaviruses can vary within a particular VP4 genotype.
\end{abstract}

This article is protected by copyright. All rights reserved. 


\section{Introduction}

Rotaviruses (family Reoviridae, subfamily Sedoreovirinae, genus Rotavirus) are the leading cause of acute dehydrating gastroenteritis in infants and young animals worldwide. ${ }^{1}$ The viral genome comprises 11 segments of double-stranded RNA, encoding six structural proteins (VP1VP4, VP6 and VP7) and six non-structural proteins (NSP1-NSP6). ${ }^{2}$ The binary classification of rotaviruses into the $\mathrm{G}$ and $\mathrm{P}$ serotypes/genotypes is based on the two outer capsid proteins, VP7 (defines G types) and the virus spike protein VP4 (defines P types), which independently elicit neutralizing antibodies and induce protective immunity. ${ }^{1} 2$ Designated genotypes are distinguished from serotypes by their listing in square brackets. Tryptic cleavage of VP4 into two fragments, designated $\mathrm{VP}^{*}$ and $\mathrm{VP} 5^{*}$, activates rotavirus particles for efficient infection. ${ }^{3-6}$ The head of the VP4 spike is formed by the VP8* carbohydrate-recognition domain that some rotavirus strains utilize to bind to sialic acid-containing glycoconjugates. ${ }^{7-14}$ Previous studies have shown that sialic acid dependency correlates with VP4 genotype specificity, which could be

the basis for host tropism, host adaptation and zoonosis. ${ }^{15,16}$ Rotavirus strains belonging to the $\mathrm{P}$

This article is protected by copyright. All rights reserved. 
genotypes [1] (bovine NCDV), [2] (simian SA11 c13), [3] (simian RRV) and [7] (porcine CRW8 and TFR-41) recognise terminal sialic acids on cell surface glycans for efficient infectivity and consequently are classified as neuraminidase (NA)-sensitive. 7 , 10,11, 13, 15, 17 Additionally, both NMR and cell-based studies identified the ganglioside GM1 as a likely receptor for some NAresistant rotavirus strains belonging to $\mathrm{P}[8]$ (human Wa, predominant globally), $\mathrm{P}[6]$ (human RV-3) and P[5] (bovine UK), and revealed that the branched (sub-terminal) sialic acid residue on GM1 is recognised by VP8*. ${ }^{811}$ Together, these findings suggested that VP8* from most NAsensitive and at least some NA-resistant rotavirus strains use sialic acid-containing glycoconjugates as their binding partners. In a new paradigm of rotavirus receptor recognition, it was shown that P[14] (human HAL1166) and P[9] (human K8) rotaviruses bind to A-type histoblood group antigen (HBGA), at the structurally equivalent location to the VP8* sialoside binding site of typical NA-sensitive rotavirus strains. ${ }^{18-21}$ Human rotavirus strains of genotypes $\mathrm{P}[14], \mathrm{P}[11]$ and $\mathrm{P}[9]$ are thought to originally have been derived from zoonotic transmission or genetic reassortment between humans and animals. ${ }^{18,21}$ Most of the studied animal strains utilize sialic acid-containing glycans for their infectivity, as demonstrated by several techniques including X-ray crystallography, STD NMR and analysis of cell interactions by VP8* and mature rotavirus virions..$^{7-9,11,13,22}$

$\mathrm{N}$-acetylneuraminic acid (Neu5Ac) and its hydroxylated derivative, $\mathrm{N}$-glycolylneuraminic acid (Neu5Gc), are the most common forms of sialic acid expressed in mammalian tissues. ${ }^{23,24}$ 
Neu5Gc is widespread in animals but not synthesised in normal human tissues due to an inactivating mutation of the CMP-N-acetylneuraminic acid hydroxylase. ${ }^{25}$ However, Neu5Gc can be metabolically incorporated into human tissues, particularly the intestine, from animalderived foods and milk products. ${ }^{26,27}$ Interestingly, most NA-sensitive rotavirus strains manifest striking discrimination in their degree of recognition of Neu5Ac and Neu5Gc, a feature that matches well with their host specificities. ${ }^{12}$ This binding specificity of VP8* protein can be translated to that exhibited by infectious rotavirus virions. ${ }^{17}$ To date, Neu5Gc binding to human rotavirus strains has not been described, which correlates with the known evolutionary loss of Neu5Gc expression in humans. ${ }^{28}$ Rotaviruses are regarded as zoonotic pathogens based on the increasing evidence reported describing the interspecies transmission of rotavirus amongst animals and from animals to humans. ${ }^{29-33}$ Common pets like dogs and cats exist in close proximity with humans, thereby posing an increased risk of zoonotic transmission (Figure 1). The genes of feline and canine rotaviruses, of serotype G3P5A and VP4 genotype P[3] specificity, share high nucleotide sequence identity, suggesting the occurrence of the interspecies transmission of rotaviruses between cats and dogs. ${ }^{34,35}$ Amongst these G3P5A[3] rotaviruses, the feline rotavirus strain Cat97, canine rotavirus strains $\mathrm{K} 9, \mathrm{CU}-1$ and A79-10, and human rotavirus strains Ro1845 and HRC3A were shown to share high nucleotide identities and form a distinct phylogenetic cluster. ${ }^{34}$ These findings highlight the importance of further exploration of rotavirus surveillance in companion animals and livestock. 
In the current study, we report the first detailed biophysical studies to determine the binding epitope of sialic acids and the preference between $\mathrm{N}$-acetyl- and $\mathrm{N}$-glycolylneuraminic acids shown by the canine K9 VP8* ${ }_{64-224}(\mathrm{G} 3 \mathrm{P} 5 \mathrm{~A}[3])$ protein. A comparable pattern of glycan binding and specificities could be expected for other rotavirus strains belonging to the VP4 serotype P5A and genotype $\mathrm{P}[3]$.

\section{Materials and methods}

\subsection{Expression and purification of recombinant canine K9 VP8* ${ }_{64-224}$}

Rotavirus strain $\mathrm{K} 9$, originally isolated from a diarrheic newborn dog, ${ }^{36,37}$ was passaged approximately four times in MA104 cells (total cell culture passages of approximately eight including the original adaption to culture). Viral dsRNA was extracted as previously described ${ }^{38}$ and used as a template for reverse transcription cDNA synthesis using the Affinity Script cDNA Synthesis Kit (Agilent) and the primer 5'-ggaattctcataatctattattaatatattcagtacatttggac-3'. Products of the reverse transcription reaction provided templates for PCR using Phusion polymerase (NEB), with forward primer 5'-cgcggatccgtattagatggaccataccaac-3' and the same primer used for the reverse transcription above as the reverse primer. The BamHI and EcoRI restriction sites in these primers (underlined) enabled insertion of the PCR product into the bacterial expression vector pGEX-4T-1 (GE Healthcare), yielding pGEX-K9-VP8* encoding amino acid residues 64224 of K9 VP4 fused to the C-terminus of GST. The integrity of the inserted VP8* gene fragment was assessed by DNA sequencing. The deduced amino acid sequence of K9 VP8*64-224

This article is protected by copyright. All rights reserved. 
is identical to this region of the published VP4 sequence (Accession No. BAA03545; Entrez Database, NCBI, NIH). The plasmid pGEX-K9-VP8* was transformed in Escherichia Coli strain BL21 (DE3) using electroporation. Escherichia Coli strain BL21 (DE3) cells containing pGEXK9-VP8* were grown at $310 \mathrm{~K}$ in Luria-Bertani medium supplemented with $150 \mu \mathrm{g} \mathrm{ml}^{-1}$ ampicillin. The overnight culture was diluted 1:10 into 4 x $500 \mathrm{ml}$ cultures supplemented with $100 \mu \mathrm{g} \mathrm{ml}^{-1}$ ampicillin. After reaching an $\mathrm{OD}_{600}$ of 0.6 , the cultures were incubated at $298 \mathrm{~K}$ for $1 \mathrm{~h}$ and then induced with $1 \mathrm{~m} M$ iso-propyl- $\beta$-D-1-thiogalactopyranoside (IPTG, BioVectra DCL). Cells were harvested $4 \mathrm{~h}$ after induction by centrifugation at $6000 \mathrm{~g}$ for $15 \mathrm{~min}$, and frozen. Cell pellets were thawed in PBS $\left(137 \mathrm{~m} M \mathrm{NaCl}, 2.7 \mathrm{~m} M \mathrm{KCl}, 10 \mathrm{~m} M \mathrm{~K}_{2} \mathrm{HPO}_{4}, 2 \mathrm{~m} M \mathrm{KH}_{2} \mathrm{PO}_{4} \mathrm{pH}\right.$ 7.4) supplemented with $1 \mathrm{~m} M$ phenylmethylsulfonyl fluoride (PMSF, Roche Diagnostics) and was lysed by sonication. The cell lysate was centrifuged at $20,000 \mathrm{~g}, 4^{\circ} \mathrm{C}$ for $30 \mathrm{~min}$ and the supernatant passed over a glutathione sepharose column (Amersham GE Healthcare) that had been pre-equilibrated with PBS. After the loading of cell lysate, the column was further equilibrated with TNC buffer (20 $\mathrm{m} M$ Tris $\left.\mathrm{pH} 8.0,100 \mathrm{~m} M \mathrm{NaCl}, 1 \mathrm{~m} M \mathrm{CaCl}_{2}\right)$. Proteolytic digestion was performed using $10 \mu \mathrm{g} \mathrm{ml}^{-1}$ TPCK-treated trypsin (Worthington Biochemical) for $2 \mathrm{~h}$ at room temperature. After digestion, a benzamidine-sepharose (Amersham GE Healthcare) column pre-equilibrated with TNC was connected in series with the glutathione-sepharose column. The protein was eluted with TNE buffer $(20 \mathrm{~m} M$ Tris $\mathrm{pH} 8.0,100 \mathrm{~m} M \mathrm{NaCl}, 1 \mathrm{~m} M$ EDTA); $1 \mathrm{~m} M$ PMSF and $2.5 \mathrm{~m} M$ benzamidine were added to the eluent. This protein was concentrated to $\sim 1 \mathrm{ml}$ using an Amicon Ultrapure-15 centrifugal filter device and analyzed for

This article is protected by copyright. All rights reserved. 
purity and molecular weight (calculated molecular weight of $18.14 \mathrm{kDa}$ ) by $15 \%$ SDS-PAGE (Supplementary Figure S1).

\subsection{Saturation transfer difference nuclear magnetic resonance (STD NMR)}

STD NMR studies were performed using our previously reported protocols ${ }^{9}$ on a Bruker 600 $\mathrm{MHz}$ Advance spectrometer with a conventional ${ }^{1} \mathrm{H} /{ }^{13} \mathrm{C} /{ }^{15} \mathrm{~N}$ gradient cryoprobe system at $288 \mathrm{~K}$. Deuterium oxide (99.9 \% deuterium, Novachem Pty Ltd (Collingwood, Australia)) was used for NMR buffer preparation. Synthesis of methyl- $\alpha$-D- $N$-acetylneuraminide (Neu5Aca2Me), as previously reported, ${ }^{39}$ was undertaken in house along with methyl- $\alpha-\mathrm{D}-N$-glycolylneuraminide (Neu5Gca2Me). Experimental samples were prepared by mixing VP8* proteins with ligand in NMR buffer (20 mM Phosphate buffer, $\mathrm{pH} 7.1,10 \mathrm{~m} M \mathrm{NaCl}$ ), giving a molar ratio of 1:100 in $300 \mu$ l. One-dimensional STD NMR was performed on K9 VP8* ${ }_{64-224}$ with Neu5Aca2Me and Neu5Gca2Me. The K9 VP8* ${ }_{64-224}$ protein was saturated at $7.13 \mathrm{ppm}$, and off-resonance was set at $33 \mathrm{ppm}$ with a cascade of 40 selective Gaussian-shaped pulses of $50 \mathrm{~ms}$ duration. A $100-\mu \mathrm{s}$ delay between each soft pulse was applied, giving a total of $2 \mathrm{~s}$ saturation time. Data were obtained with an interspersed acquisition of pseudo-two-dimensional on-resonance and offresonance spectra. These spectra were processed separately to obtain the final STD NMR spectrum by subtracting individual on- and off-resonance spectra. Control STD NMR experiments were also performed using an identical experimental setup and ligand concentration but in the absence of the protein.

This article is protected by copyright. All rights reserved. 


\subsection{Isothermal titration calorimetry (ITC)}

K9 VP8* and ligands were prepared in TNE buffer. Samples were degassed prior to use. Experiments were conducted with $0.3 \mathrm{~m} M \mathrm{~K} 9-\mathrm{VP}{ }^{*}$ and $2 \mathrm{~m} M$ ligand. Titrations were performed in a TA NanoAnalyze calorimeter using 20 injections applied 300 seconds apart. Each injection dispensed $2.5 \mu \mathrm{l}$ of ligand into the sample cell containing $300 \mu \mathrm{l}$ of K9 VP8*, at 200 rpm. Titration and blank data were collected at room temperature, and binding isotherms were fitted using NanoAnalyze v3.7 software. Binding curves are representative of two independent measurements. Table 1 has mean of all binding constants \pm standard error mean.

\subsection{Homology modelling and structure validation.}

The homology model of canine K9 VP8* ${ }_{64-224}$ was constructed using the SWISS-MODEL server $^{40}$ based on amino-acid sequence alignment with RRV VP8* (80.12 \% amino-acid sequence identity) and the three-dimensional protein structure of RRV VP8* ${ }_{62-224}(\mathrm{PDB}: 1 \mathrm{KQR}$

$\left.{ }^{41}\right)$. The global model quality estimation (GMQE) score was 0.96 which reflects a high accuracy of the model built based on the sequence alignment and template, and QMEAN (Qualitative Model Energy Analysis) Z-score was 0.66 indicating the overall quality of the model is reliable. $^{42,43}$

\section{Results and discussion}

\subsection{STD NMR studies of Neu5Aca2Me and Neu5Gco2Me interactions with K9 VP8*}

This article is protected by copyright. All rights reserved. 
The neuraminic acid derivatives Neu5Aca2Me and Neu5Gca2Me represent the minimal sialosides with a defined anomeric state that VP8* proteins from NA-sensitive animal rotaviruses recognise and bind. ${ }^{7}{ }^{17}$ Some animal rotavirus strains (CRW-8, NCDV, RRV and UK) have been reported to interact with the glycerol side chain, $N$-acetamide (NHAc) group, and the carboxylic acid group of the sialic acid residue of gangliosides. ${ }^{7,-13}$ We have used STD NMR to examine the interaction of the $N$-acetyl and $N$-glycolyl derivatives Neu5Aca2Me and Neu5Gca2Me with canine K9 VP8*. In the STD NMR spectrum of K9 VP8*64-224 protein in the presence of Neu5Aca2Me, the greatest STD effect was observed for the methyl group of the acetyl (NHAc) moiety at approximately $1.85 \mathrm{ppm}$ (Figure 2A). This is consistent with previously published studies, showing an interaction of the NHAc group with VP8* proteins. $^{7,9,17,44}$ Similarly, the glycolyl group (NHGc) of Neu5Gca2Me makes contact with the K9 VP8*64-224 protein, as shown by the STD signal at $\sim 3.9 \mathrm{ppm}$ (Figure 2B). In the crystal structure of RRV (1KQR and $3 \mathrm{~TB} 0)^{17,44}$ and also CRW-8 VP8* with this ligand (2I2S and 3TAY) ${ }^{7,17}$, the carboxylic group interacts with the protein, engaging in hydrogen bonding with the backbone proton and also the hydroxyl group proton of Ser190. In the STD NMR experiments the carboxylic acid group would be deprotonated due to the buffer maintaining a $\mathrm{pH}$ slightly above neutral. The control STD NMR spectra of Neu5Ac $\alpha 2 \mathrm{Me}$ and Neu5Gca2Me (without the protein) reveal no significant STD signals (data not shown). The methyl aglycon ( ${ }^{1} \mathrm{H}$ at $\sim 3.14 \mathrm{ppm}$ ) does not show a binding signal in the STD NMR spectrum (Figure 2), indicating that this aglycon unit of both Neu5Gca2Me and Neu5Aca2Me is not involved in direct interactions with K9 VP8*. This

This article is protected by copyright. All rights reserved. 
correlates well with observations in other animal rotavirus strains such as CRW-8 and RRV. 7,9, 17 Our findings show that in solution K9 VP8* interacts with $N$-acetyl- and $N$-glycolylneuraminic acid derivatives in a similar fashion as reported previously for the $\mathrm{P}[7](\mathrm{CRW}-8)$ and $\mathrm{P}[3](\mathrm{RRV})$ rotavirus strains. In addition, our NMR data for the VP8* complex with Neu5Aca2Me and Neu5Gca2Me are in a good agreement with the X-ray crystallographic complex structures of the VP8* of other animal rotaviruses. ${ }^{7,9,17,44}$ Our data demonstrate that K9 VP8* recognises sialic acid-containing glycans as potential binding partners and shares the comparable sialic acidbinding epitope with several NA-sensitive animal rotaviruses.

\subsection{Characterization of the neuraminic acid binding preference of K9 VP8*}

Binding of some rotavirus strains to sialic acid-containing glycans is one of the critical steps for infection of host cells. Interestingly, rotaviruses exhibit distinct glycan specificity, which may be an essential determinant that restricts its spread amongst different species. NA-sensitive animal rotavirus strains NCDV, OSU, CRW-8, and SA11 have shown a preference for Neu5Gc over Neu5Ac, which contrasts with the RRV (P5B[3]) preference. ${ }^{12,17,41,45}$ The distinct binding preference of RRV was explained by amino acid variations in the VP8* carbohydrate binding site. ${ }^{17}$ The amino acid at position 187 of VP8* is a glycine in most NA-sensitive animal strains, whereas RRV has a lysine (Figure 3). The presence of lysine in RRV has ability to cause steric hindrance with the hydroxyl group of the $N$-glycolyl moiety of Neu5Gc. ${ }^{17,46}$ It has been proposed that the amino acid at position 187 in NA-sensitive rotavirus VP8* could influence the 
binding preference toward sialic acid derivatives, whereas the amino acid at position 157 affects VP8* binding affinity rather than carbohydrate specificity (Figure 3 ). ${ }^{17}$ In canine rotavirus K9 VP8*, proline and glycine are located at positions 157 and 187, respectively. Based on the above considerations it is anticipated that K9 VP8* would show preference for Neu5Gc over Neu5Ac. ITC was used to investigate the binding affinities of Neu5Ac $\alpha 2 \mathrm{Me}$ and Neu5Gc $\alpha 2 \mathrm{Me}$ towards K9 VP8* protein (Figure 4). The $\mathrm{K}_{\mathrm{d}}$ values obtained for Neu5Aca2Me (Figure 4A) and Neu5Gca2Me (Figure 4B) are $50.32 \mu M$ and $27.50 \mu M$ respectively (Table 1). The K9 VP8* shows preference for the glycolyl over the acetyl neuraminc acid derivative, further supporting the hypothesis that the glycan specificity is influenced by the presence of glycine at position 187. This is consistent with previously reported binding affinities for VP8* of OSU and CRW-8, both having glycine at position 187 , that showed a minimum three-fold higher affinity for the $N$ glycolyl over the $N$-acetyl derivative. ${ }^{12}$

\subsection{Homology modelling of K9 VP8* $64-224$}

The specificity and affinity shown by canine K9 VP8* towards $N$-glycolylneuraminic acid has led us to generate its homology model to analyze the predicted three-dimensional arrangements of the amino acids. To examine our computational model of K9 VP8*64-224, QMEAN was calculated, which is a composite scoring function based on distinct geometrical properties and

This article is protected by copyright. All rights reserved. 
yields an absolute quality estimate on the basis of one single model. The QMEAN score ranges between 0 to 1 , with a value closer to 1 reflecting a better quality of the model. The QMEAN tool provides the local quality plot that shows the expected resemblance of each residue to the native structure. The local quality plot (Supplementary Figure S2) for K9 VP8*64-224 model demonstrates that all the residues have high similarity to the target, indicating lower per residue error. The QMEAN Z-score for the current homology model (0.66) was compared with the Zscore of all the high-resolution crystal structure of similar size and is plotted in comparison plot (Supplementary Figure S3). Thus, the quality indicators demonstrated that the K9 VP8*64-224 homology modeled structure is highly reliable. Structural superimposition $\left(\mathrm{C}_{\alpha}\right.$ atoms $)$ of the canine K9 (P5A[3]) VP8*64-224 homology model (by nature of the modelling is identical to the rhesus RRV (P5B[3]) with root mean square deviation (r.m.s.d) of $0.06 \AA$ ) gives an r.m.s.d of $\sim 0.51 \AA$ when compared to porcine CRW-8 (P[7]) VP8*, showing an overall comparable fold of the VP8* protein domain (Figure 5). Closer inspection discloses important differences, notably the alternative conformation state of the Gly156-Pro157 peptide bond (Figure 5B). Proline is the predominant residue at position 157 of NA-sensitive animal rotaviruses with serine (simian SA11, bovine NCDV) being the primary alternative. The presence of proline would impart conformational flexibility to the protein chain due to cis- and trans-isomerization, which would vary the polarity of the surface of sialic acid binding cleft by altering the direction of the carbonyl group of Gly156. Such flexibility is observed in the crystal structure of RRV VP8* (PDB: 1KQR), where the Gly156-Pro157 peptide bond can take on both cis- and trans- 
conformations, with trans (where the Gly156 carbonyl is directed into the binding-site) being dominant. ${ }^{44}$ Based on Psi-Blast profiles and secondary structure information a cis- peptide bond was predicted for Pro157 using CISPEPpred server ${ }^{47}$ ( http://sunflower.kuicr.kyoto-u.ac.jp) for K9, RRV and CRW-8 VP8*, giving indication that this peptide bond could have a tendency to easily undergo cis-trans isomerisation. Our generated K9 VP8*3D model presented the Gly156Pro157 peptide bond in a cis-conformation, whereas it is trans in most of sialoside complexed VP8* crystal structures (Figure 5B). A sodium ion has been observed in some NA-sensitive VP8* crystal structures to coordinate with the carbonyl of Gly156, and appears to stabilise the Gly156-Pro157 peptide bond in the trans-conformation, however, the specific biological role of the sodium ion at this site remains unclear. ${ }^{7,12,13,17,22}$ Site-directed mutagenesis from proline to serine showed a significant reduction in the affinity of $N$-acetylneuraminic acid, and thus reflects the importance of proline at position $157 .{ }^{17}$ Interestingly, the canine rotavirus K9 VP8* $\left(\mathrm{K}_{\mathrm{d}} \sim 50\right.$ $\mu \mathrm{M})$ showed over fivefold higher affinity for Neu5Aca2Me when compared to porcine CRW-8 $(\sim 270 \mu M){ }^{17}$ and rhesus RRV $(\sim 300 \mu M){ }^{22}$. Our STD NMR data demonstrated that the ligand $\mathrm{N}$-acetyl or $\mathrm{N}$-glycolyl group actively engages with $\mathrm{K} 9 \mathrm{VP} 8 *$ and thus the local environment in this region of the protein could alter the specificity and/or affinity of the specific carbohydrates. The Gly156-Pro157 segment lies adjacent to the $N$-acetyl group of Neu5Aca2Me and thus its flexibility may influence its binding (Figure 5C). The residues forming the sialic acid binding sites are highly conserved among NA-sensitive rotavirus strains (Figure 3). The K9 VP8* has a serine instead of asparagine (RRV and CRW-8) at the 178 position, which is in close proximity 
to the $N$-acetyl group of the $N$-acetylneuraminic acid (Figure 3, Figure 5). Thus, the less bulky serine at 178 position in $\mathrm{K} 9$ would alter the local environment of sialic acid binding site and may influence the binding of $\mathrm{N}$-acetylneuraminic acid (Figure 5). The amino acid sequence alignment of VP8* from different rotavirus strains shows that the canine K9 VP8* (P5A[3]) shares 98\% and $96 \%$ sequence identity to that of human rotaviruses HCR-3A and Ro1845, respectively (Figure 3). The sialic acid binding site on the VP8* domain is highly conserved across most NAsensitive animal rotaviruses, and is also conserved in some human strains like HCR-3A and Ro1845, suggesting that these may recognise host cell sialic acids similarly to the animal strains. The presence of the same amino acids at positions 157,187 , and 178 further suggests that the P5A[3] rotaviruses K9, HCR-3A and Ro1845 could all have equivalent preferences and affinity for the $N$-glycolyl- and $N$-acetyl- forms of sialic acid-containing gangliosides.

\section{Conclusion}

Multiple rotavirus strains exhibit a degree of restriction to a particular host species. Speciesspecific strains are more frequently identified compared to interspecies strains. ${ }^{16}$ The zoonotic potential of rotaviruses has increased the burden and challenges in control of rotavirus disease. The rotavirus VP8* mediates initial interaction with cellular glycans, which is a critical step for viral pathogenesis, host restriction, and zoonotic transmission. The glycan binding has been

previously shown to be translated to that exhibited by infectious rotavirus particles ${ }^{17,20}$. Our results demonstrate that canine $\mathrm{K} 9$ (P5A[3]) VP8*, and by inference the virions, possesses the 
ability to bind both $N$-glycolyl- and $N$-acetyl- derivatives of sialic acid, with a preference for the $N$-glycolyl form. This contrasts the well-established preference of the $\mathrm{P} 5 \mathrm{~B}[3]$ rotavirus strain RRV for $N$-acetylneuraminic acid over the $N$-glycolyl form, ${ }^{13,17,41}$ and demonstrates that the receptor preference of rotaviruses can vary between the subtypes (A and B) within a VP4 serotype (P5) and also within a VP4 genotype (P[3]). The variation in the sialic acid binding cleft region amongst rotavirus strains could influence the recognition and the binding of rotaviruses with cellular glycan receptors to some extent. The higher affinity for Neu5Aca2Me shown by

subtype A over subtype B, further suggests that animal rotaviruses of the P5A serotype (canine K9) could bind efficiently to the glycans that are expressed in the human intestine. Our studies provide crucial information for understanding the initial rotavirus-cell engagement and adaptation to intestinal replication in alternative hosts.

\section{Acknowledgements}

Financial support from the National Health and Medical Research Council of Australia (ID1085596 awarded to M.v.I., B.S.C., H.B.) is gratefully acknowledged.

This article is protected by copyright. All rights reserved. 


\section{References}

1. Estes MK, Greenberg HB. Rotaviruses. sixth ed. Philadelphia: Wolters Kluwer Health/Lippincott, Williams and Wilkins; 2013.

2. Desselberger U. Rotaviruses. Virus Res. 2014;190:75-96. doi: 10.1016/j.virusres.2014.06.016.

3. Estes MK, Graham DY, Mason BB. Proteolytic enhancement of rotavirus infectivity: molecular mechanisms. J Virol. 1981;39(3):879-888.

4. Konno $\mathrm{T}$, Suzuki $\mathrm{H}$, Kitaoka $\mathrm{S}$, et al. Proteolytic enhancement of human rotavirus infectivity. Clin Infect Dis. 1993;16 Suppl 2:S92-97.

5. Arias CF, Romero P, Alvarez V, Lopez S. Trypsin activation pathway of rotavirus infectivity. J Virol. 1996;70(9):5832-5839.

6. Crawford SE, Mukherjee SK, Estes MK, et al. Trypsin Cleavage Stabilizes the Rotavirus VP4 Spike. J Virol. 2001;75(13):6052-6061. doi: 10.1128/jvi.75.13.6052-6061.2001.

7. Blanchard $\mathrm{H}, \mathrm{Yu} \mathrm{X}$, Coulson BS, von Itzstein $\mathrm{M}$. Insight into host cell carbohydrate-recognition by human and porcine rotavirus from crystal structures of the virion spike associated carbohydratebinding domain (VP8*). J Mol Biol. 2007;367(4):1215-1226. doi: 10.1016/j.jmb.2007.01.028.

8. Fleming FE, Bohm R, Dang VT, et al. Relative roles of GM1 ganglioside, N-acylneuraminic acids, and alpha2beta1 integrin in mediating rotavirus infection. J Virol. 2014;88(8):4558-4571. doi: 10.1128/JVI.03431-13.

9. Haselhorst $\mathrm{T}$, Blanchard $\mathrm{H}$, Frank $\mathrm{M}$, et al. STD NMR spectroscopy and molecular modeling investigation of the binding of $\mathrm{N}$-acetylneuraminic acid derivatives to rhesus rotavirus VP8* core. Glycobiology. 2007;17(1):68-81. doi: 10.1093/glycob/cwl051.

10. Haselhorst T, Fiebig $T$, Dyason JC, et al. Recognition of the GM3 ganglioside glycan by Rhesus rotavirus particles. Angew Chem Int Ed Engl. 2011;50(5):1055-1058. doi: 10.1002/anie.201004116.

11. Haselhorst T, Fleming FE, Dyason JC, et al. Sialic acid dependence in rotavirus host cell invasion. Nat Chem Biol. 2009;5(2):91-93. doi: 10.1038/nchembio.134.

12. Yu X, Blanchard H. Carbohydrate recognition by rotaviruses. J Struct Funct Genomics. 2014;15(3):101-106. doi: 10.1007/s10969-013-9167-5.

13. Yu X, Coulson BS, Fleming FE, et al. Novel structural insights into rotavirus recognition of ganglioside glycan receptors. J Mol Biol. 2011;413(5):929-939. doi: 10.1016/j.jmb.2011.09.005.

14. Coulson BS. Expanding diversity of glycan receptor usage by rotaviruses. Curr Opin Virol. 2015;15:90-96. doi: 10.1016/j.coviro.2015.08.012.

15. Ciarlet $\mathrm{M}$, Ludert JE, Iturriza-Gomara $\mathrm{M}$, et al. Initial interaction of rotavirus strains with $\mathrm{N}$ acetylneuraminic (sialic) acid residues on the cell surface correlates with VP4 genotype, not species of origin. J Virol. 2002;76(8):4087-4095.

16. Martella V, Banyai K, Matthijnssens J, Buonavoglia C, Ciarlet M. Zoonotic aspects of rotaviruses. Vet Microbiol. 2010;140(3-4):246-255. doi: 10.1016/j.vetmic.2009.08.028.

This article is protected by copyright. All rights reserved. 
17. Yu X, Dang VT, Fleming FE, et al. Structural basis of rotavirus strain preference toward N-acetylor N-glycolylneuraminic acid-containing receptors. J Virol. 2012;86(24):13456-13466. doi: 10.1128/JVI.06975-11.

18. Hu L, Crawford SE, Czako R, et al. Cell attachment protein VP8* of a human rotavirus specifically interacts with A-type histo-blood group antigen. Nature. 2012;485(7397):256-259. doi: 10.1038/nature10996.

19. Huang $\mathrm{P}, \mathrm{Xia} \mathrm{M}$, Tan $\mathrm{M}$, et al. Spike protein VP8* of human rotavirus recognizes histo-blood group antigens in a type-specific manner. J Virol. 2012;86(9):4833-4843. doi: 10.1128/JVI.0550711.

20. Bohm R, Fleming FE, Maggioni A, et al. Revisiting the role of histo-blood group antigens in rotavirus host-cell invasion. Nat Commun. 2015;6:5907. doi: 10.1038/ncomms6907.

21. Yu X, Mishra R, Holloway G, et al. Substantial Receptor-induced Structural Rearrangement of Rotavirus VP8*: Potential Implications for Cross-Species Infection. Chembiochem. 2015;16(15):2176-2181. doi: 10.1002/cbic.201500360.

22. Kraschnefski MJ, Bugarcic A, Fleming FE, et al. Effects on sialic acid recognition of amino acid mutations in the carbohydrate-binding cleft of the rotavirus spike protein. Glycobiology. 2009;19(3):194-200. doi: 10.1093/glycob/cwn119.

23. Wang B. Molecular mechanism underlying sialic acid as an essential nutrient for brain development and cognition. Adv Nutr. 2012;3(3):465S-472S. doi: 10.3945/an.112.001875.

24. Diaz SL, Padler-Karavani V, Ghaderi D, et al. Sensitive and specific detection of the non-human sialic Acid N-glycolylneuraminic acid in human tissues and biotherapeutic products. PLoS One. 2009;4(1):e4241. doi: 10.1371/journal.pone.0004241.

25. Davies LR, Varki A. Why Is N-Glycolylneuraminic Acid Rare in the Vertebrate Brain? Top Curr Chem. 2015;366:31-54. doi: 10.1007/128_2013_419.

26. Tangvoranuntakul $P$, Gagneux $P$, Diaz $S$, et al. Human uptake and incorporation of an immunogenic nonhuman dietary sialic acid. Proc Natl Acad Sci U S A. 2003;100(21):12045-12050. doi: 10.1073/pnas.2131556100.

27. Byres E, Paton AW, Paton JC, et al. Incorporation of a non-human glycan mediates human susceptibility to a bacterial toxin. Nature. 2008;456(7222):648-652. doi: 10.1038/nature07428.

28. Muchmore EA, Diaz S, Varki A. A structural difference between the cell surfaces of humans and the great apes. Am J Phys Anthropol. 1998;107(2):187-198. doi: 10.1002/(SICI)10968644(199810)107:2<187::AID-AJPA5>3.0.CO;2-S.

29. Matthijnssens J, De Grazia S, Piessens J, et al. Multiple reassortment and interspecies transmission events contribute to the diversity of feline, canine and feline/canine-like human group A rotavirus strains. Infect Genet Evol. 2011;11(6):1396-1406. doi: 10.1016/j.meegid.2011.05.007.

30. Ben Hadj Fredj M, Heylen E, Zeller M, et al. Feline origin of rotavirus strain, Tunisia, 2008. Emerg Infect Dis. 2013;19(4):630-634. doi: 10.3201/eid1904.121383.

31. Bonica MB, Zeller M, Van Ranst M, Matthijnssens J, Heylen E. Complete genome analysis of a rabbit rotavirus causing gastroenteritis in a human infant. Viruses. 2015;7(2):844-856. doi: 10.3390/v7020844.

This article is protected by copyright. All rights reserved. 
32. Gautam R, Mijatovic-Rustempasic S, Roy S, et al. Full genomic characterization and phylogenetic analysis of a zoonotic human G8P[14] rotavirus strain detected in a sample from Guatemala. Infect Genet Evol. 2015;33:206-211. doi: 10.1016/j.meegid.2015.05.004.

33. Zhou X, Wang YH, Ghosh S, et al. Genomic characterization of G3P[6], G4P[6] and G4P[8] human rotaviruses from Wuhan, China: Evidence for interspecies transmission and reassortment events. Infect Genet Evol. 2015;33:55-71. doi: 10.1016/j.meegid.2015.04.010.

34. Tsugawa $T$, Hoshino $Y$. Whole genome sequence and phylogenetic analyses reveal human rotavirus G3P[3] strains Ro1845 and HCR3A are examples of direct virion transmission of canine/feline rotaviruses to humans. Virology. 2008;380(2):344-353. doi:

10.1016/j.virol.2008.07.041.

35. Gauchan P, Sasaki E, Nakagomi T, et al. Whole genotype constellation of prototype feline rotavirus strains FRV-1 and FRV64 and their phylogenetic relationships with feline-like human rotavirus strains. J Gen Virol. 2015;96(Pt 2):338-350. doi: 10.1099/vir.0.070771-0.

36. Fulton RW, Johnson CA, Pearson NJ, Woode GN. Isolation of a rotavirus from a newborn dog with diarrhea. Am J Vet Res. 1981;42(5):841-843.

37. Zheng SL, Woode GN, Melendy DR, Ramig RF. Comparative studies of the antigenic polypeptide species VP4, VP6, and VP7 of three strains of bovine rotavirus. J Clin Microbiol. 1989;27(9):19391945.

38. Dyall-Smith ML, Holmes IH. Sequence homology between human and animal rotavirus serotypespecific glycoproteins. Nucleic Acids Res. 1984;12(9):3973-3982.

39. Kononov LO, Kornilov AV, Sherman AA, et al. [Synthesis of oligosaccharides related to HNK-1 antigen. 2. Synthesis of 3'"-O-(3-O-sulfo-beta-D-glucuronopyranosyl)-lacto-N-neotetrao se betapropylglycoside]. Bioorg Khim. 1998;24(8):608-622.

40. Arnold K, Bordoli L, Kopp J, Schwede T. The SWISS-MODEL workspace: a web-based environment for protein structure homology modelling. Bioinformatics. 2006;22(2):195-201. doi: 10.1093/bioinformatics/bti770.

41. Dormitzer PR, Sun ZY, Blixt O, et al. Specificity and affinity of sialic acid binding by the rhesus rotavirus VP8* core. J Virol. 2002;76(20):10512-10517.

42. Benkert $P$, Tosatto $S C$, Schomburg D. QMEAN: A comprehensive scoring function for model quality assessment. Proteins. 2008;71(1):261-277. doi: 10.1002/prot.21715.

43. Benkert $P$, Biasini $M$, Schwede $T$. Toward the estimation of the absolute quality of individual protein structure models. Bioinformatics. 2011;27(3):343-350. doi:

10.1093/bioinformatics/btq662.

44. Dormitzer PR, Sun ZY, Wagner G, Harrison SC. The rhesus rotavirus VP4 sialic acid binding domain has a galectin fold with a novel carbohydrate binding site. EMBO J. 2002;21(5):885-897. doi: 10.1093/emboj/21.5.885.

45. Delorme $\mathrm{C}$, Brussow $\mathrm{H}$, Sidoti J, et al. Glycosphingolipid binding specificities of rotavirus: identification of a sialic acid-binding epitope. J Virol. 2001;75(5):2276-2287. doi: 10.1128/JVI.75.5.2276-2287.2001.

46. Isa P, Arias CF, Lopez S. Role of sialic acids in rotavirus infection. Glycoconj J. 2006;23(1-2):27-37. doi: 10.1007/s10719-006-5435-y.

This article is protected by copyright. All rights reserved. 
47. Song J, Burrage K, Yuan Z, Huber T. Prediction of cis/trans isomerization in proteins using PSIBLAST profiles and secondary structure information. BMC Bioinformatics. 2006;7:124-124. doi: 10.1186/1471-2105-7-124.

48. Sievers $F$, Wilm $A$, Dineen $D$, et al. Fast, scalable generation of high-quality protein multiple sequence alignments using Clustal Omega. Mol Syst Biol. 2011;7:539. doi: 10.1038/msb.2011.75.

49. Bond CS, Schuttelkopf AW. ALINE: a WYSIWYG protein-sequence alignment editor for publication-quality alignments. Acta Crystallogr D Biol Crystallogr. 2009;65(Pt 5):510-512. doi: $10.1107 / \mathrm{s} 0907444909007835$.

\section{TABLES}

Table 1 Isothermal titration calorimetry data statistics

\begin{tabular}{|l|c|c|c|c|c|l|}
\hline Protein & ligand & $\mathbf{K}_{\mathbf{d}}(\boldsymbol{\mu M})$ & $\mathbf{N}$ & $\Delta \mathbf{H}(\mathbf{k J} / \mathbf{m o l})$ & $\mathbf{K}_{\mathbf{a}}\left(\mathbf{1 0}^{\mathbf{4}} \mathbf{M}^{-}\right.$ & $\Delta \mathbf{S}(\mathbf{J} / \mathbf{m o l}-\mathbf{K})$ \\
& & & & & & \\
& & & & & & \\
\hline \multirow{2}{*}{ Canine } & Neu5Ac $\alpha 2 \mathrm{Me}$ & $50.32 \pm 5.23$ & $1.16 \pm 0.14$ & $-1.42 \pm 1.27$ & $1.99 \pm 0.20$ & $77.54 \pm 3.41$ \\
\cline { 2 - 7 } & & & & & & \\
\hline
\end{tabular}

This article is protected by copyright. All rights reserved. 


\begin{tabular}{|l|l|l|l|l|l|l|}
\hline VP8* & & & & & & \\
\hline
\end{tabular}

\section{Figure Legends}

Figure 1 . Inter-species and zoonotic transmission of rotaviruses. The VP8* sub-domain of rotaviruses makes initial contact with host cell surface glycoconjugates. Neu5Gc is widespread in animals but not synthesized in human tissue (expresses Neu5Ac). Common pets for example feline and canine act as the reservoir for the specific genotype and are capable of

This article is protected by copyright. All rights reserved. 
transmitting among themselves. Human-pet interaction often leads to the introduction of animal rotaviruses into the humans and thus the emergence of new human strains. Rotaviruses belonging to G3P5A serotype usually infect canine/feline and has also been identified in humans showed preference for Neu5Gc, contrasting G3P5B serotype (isolated from simian) that prefer Neu5Ac.

Figure 2. STD NMR studies of canine $\mathrm{K} 9 \mathrm{VP} 8 *_{64-224}$ with $N$-acetyl and $N$-glycolylneuraminic acid derivatives. (A) STD NMR analysis of K9 VP8*64-224 with Neu5Aca2Me. (i) ${ }^{1} \mathrm{H}$ NMR spectrum of Neu5Aca2Me; (ii) STD NMR spectrum of Neu5Aca2Me in the presence of VP8* at a protein-ligand molar ratio of 1:100. The methyl group of the NHAc moiety gives an STD signal at $\sim 1.85 \mathrm{ppm}$ (indicated by an arrow). (B) STD NMR analysis of K9 VP8*64-224 with

Neu5Gca2Me. (i) ${ }^{1} \mathrm{H}$ NMR spectrum of Neu5Gca2Me; (ii) STD NMR spectrum of Neu5Gca2Me in the presence of VP8* at a protein-ligand molar ratio of 1:100. The methylene group of the NHGc gives a signal at $\sim 3.9 \mathrm{ppm}$ (indicated by an arrow).

Figure 3. Amino acid sequence alignment of VP8* from animal rotaviruses K9 (P5A[3]), RRV(P5B[3]), CRW-8 (P9[7]) and TFR-41 (P9[7]) and human rotaviruses HCR-3A (P5A[3]), Ro 1845 (P5A[3]), Wa (P1A[8]) and DS-1 (P1B[4)]. The VP8* sequences of Wa and DS-1 have a deletion at position 135 (indicated by a solid red triangle). VP8* sialic acid-binding amino acids (Arg101, His/Tyr155, Tyr188, and Tyr189) that are conserved amongst animal rotaviruses

This article is protected by copyright. All rights reserved. 
K9, TFR-41, CRW-8, and RRV and human rotaviruses HCR-3A and Ro1845, are indicated by red stars. Amino acids at position 157, 178, and 187 are highlighted in red. The multiple sequence alignment was performed by Clustal Omega. ${ }^{48}$ The Alignment diagram was generated by ALINE. ${ }^{49}$ Black to white gradient indicates the decreasing conservation.

Figure 4. ITC analysis of K9 VP8* ${ }_{64-224}$ binding to Neu5Aca2Me (A) and Neu5Gca2Me (B). The average $\mathrm{K}_{\mathrm{d}}$ value for each combination was calculated with $\mathrm{n}$ set to 1 (values in Table 1).

Figure 5. (A) Superimposition of the canine K9 VP8* homology model with crystal structures of rhesus RRV VP8* and porcine CRW-8 VP8*. Cartoon representation with red helix and the $\beta$ strands and loops of K9, RRV, and CRW-8 VP8* colored yellow, cyan, and green respectively. The Gly156-Pro157 segment region is indicated by a red arrow. (B) Superimposition of residues forming the sialic acid binding site of K9 (yellow stick), RRV (cyan stick) and CRW-8 (green stick). The residues showing differences are labeled in red. RRV has lysine at position 187 (note that there are 2 sidechain conformations) instead of glycine (K9 and CRW-8). K9 has serine at position 178 instead of asparagine that is found in RRV and CRW-8. (C) The sialic acid binding cleft region in the homology model of K9 VP8* with the superimposed RRV VP8* in complex with Neu5Aca2Me (PDB: 1KQR). K9 VP8* is in a surface representation (carbon, nitrogen and 
oxygen atoms colored in white, blue, and red respectively). The Neu5Aca2Me molecule is depicted in yellow stick form and the RRV VP8* is excluded from the figure for clarity. 

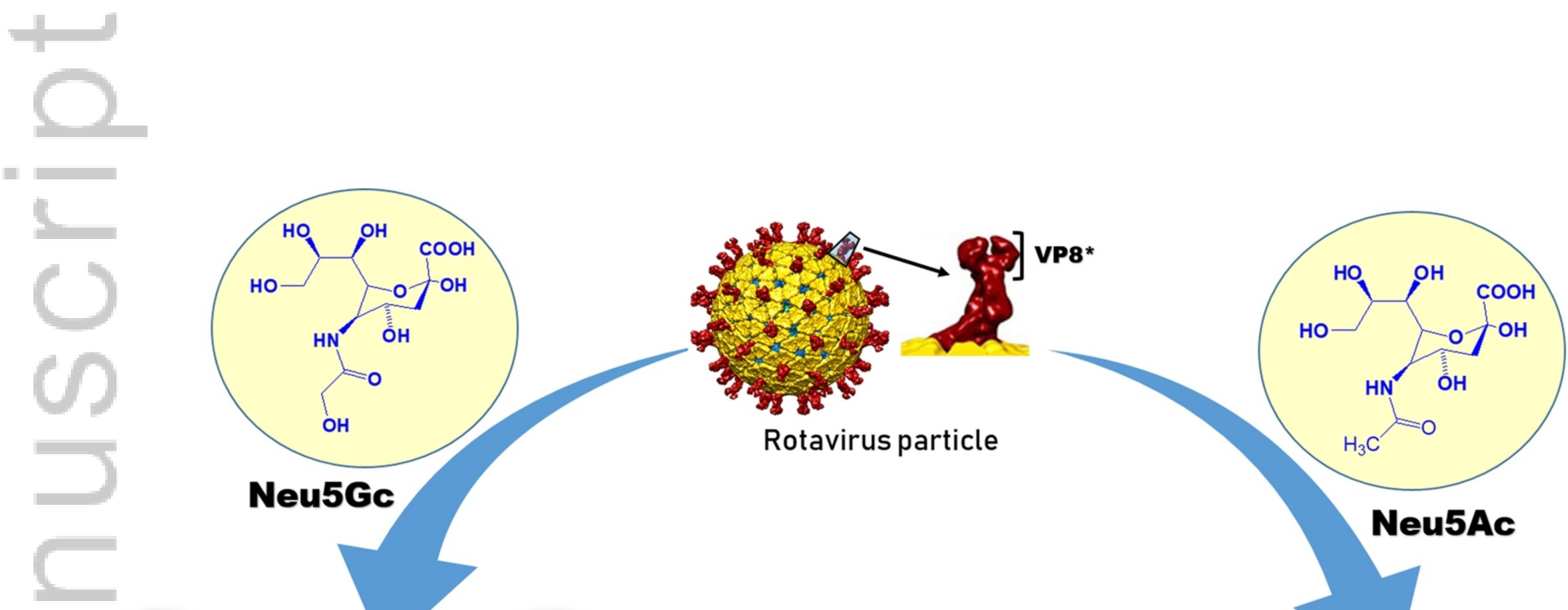

Neu5Gc

Feline rotaviruses (G3P5A[3], prefer Neu5Gc)

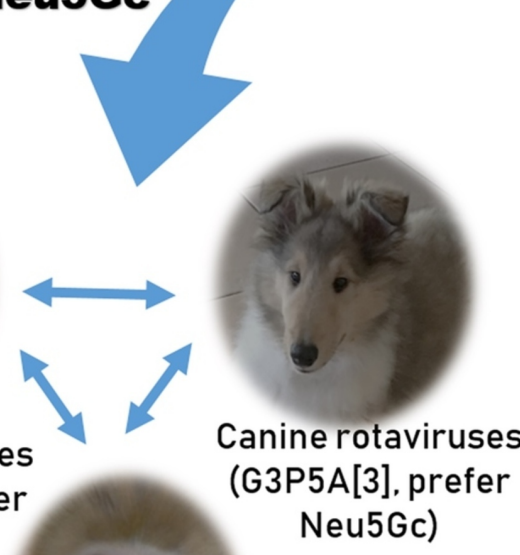

0 Neu5Gc)

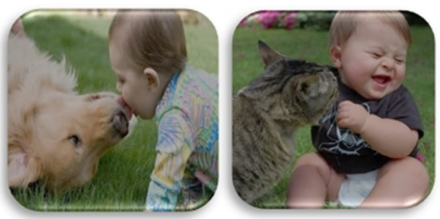

Human-pet interaction

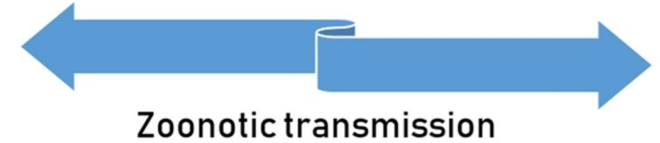

Zoonotic transmission

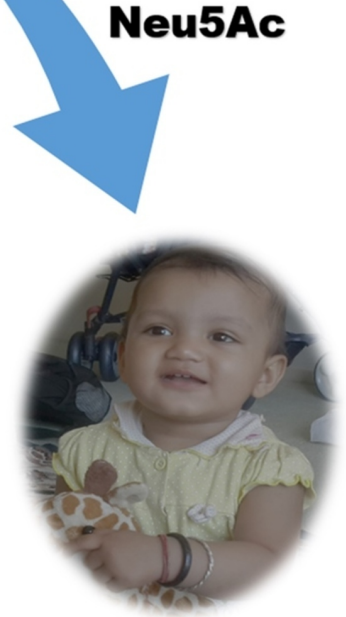

Human rotaviruses (strain HCR3A \& Ro1845 (G3P5A[3]))

Simian rotaviruses

(G3P5B[3], prefer Neu5AC)

JMR_2718_F1.jpeg 
A
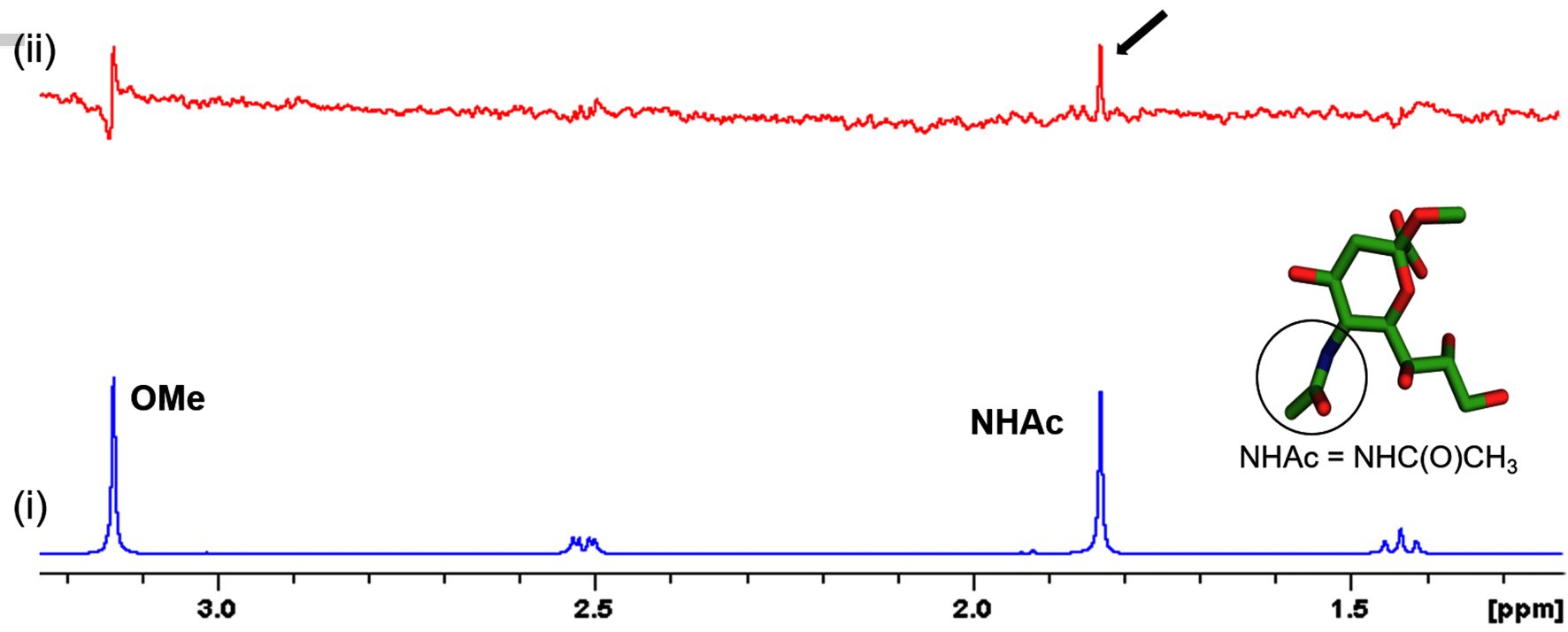

B

(ii)

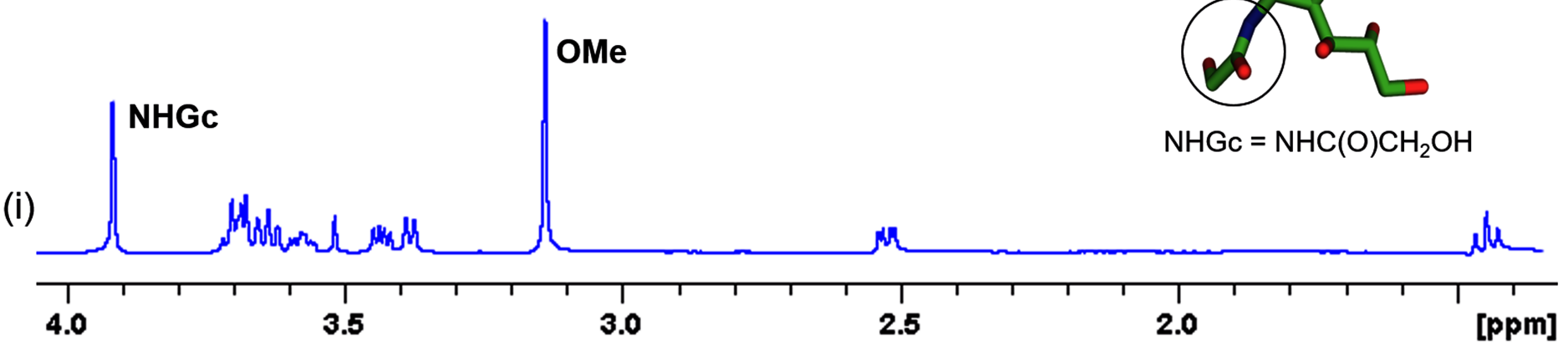


Canine $K 9$ Rhesus RRV Porcine CRW8 Human HCR-3A Human Ro 1845 Human Wa Human Wa

Canine $\mathrm{Kg}$ Rhesus RRV Porcine CRW8 Porcine TFR-4 Human HCR-3A Human Ro 1845 Human Wa Human DS-1

Canine K9 Rhesus RRV Porcine CRW8 Porcine TFR-41 Human HCR-3A Human Ro 1845 Human Wa Human Wa
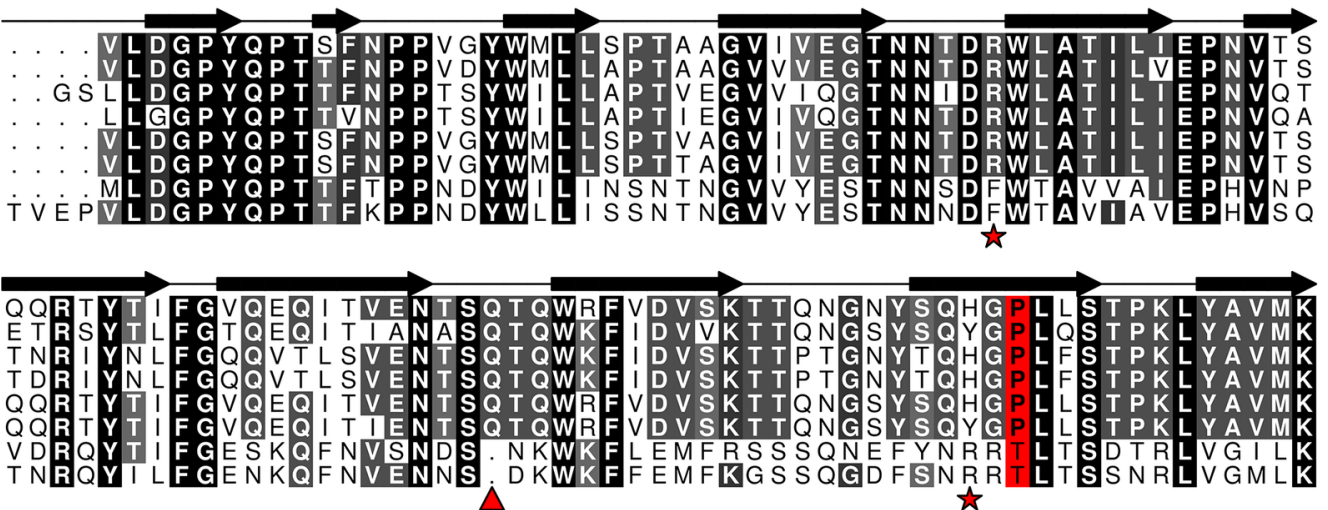

169
169
169
169
169
169
168
168
$\dot{\Delta}$
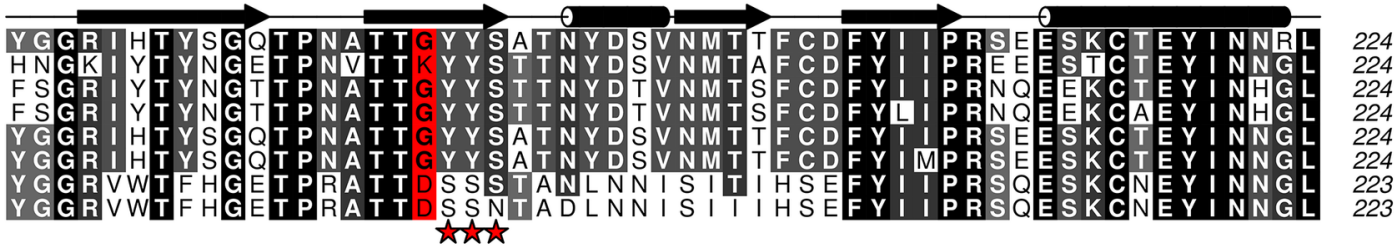

JMR_2718_F3.tif

This article is protected by copyright. All rights reserved. 
A

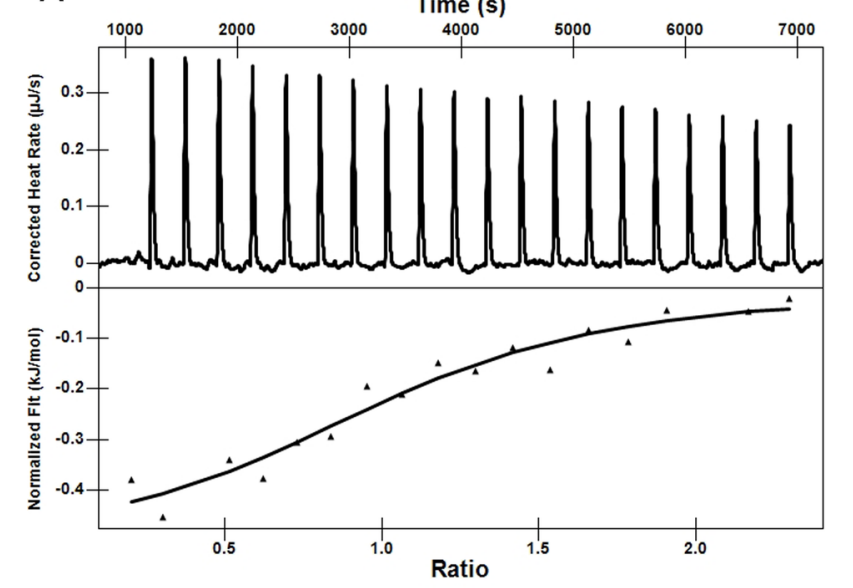

B

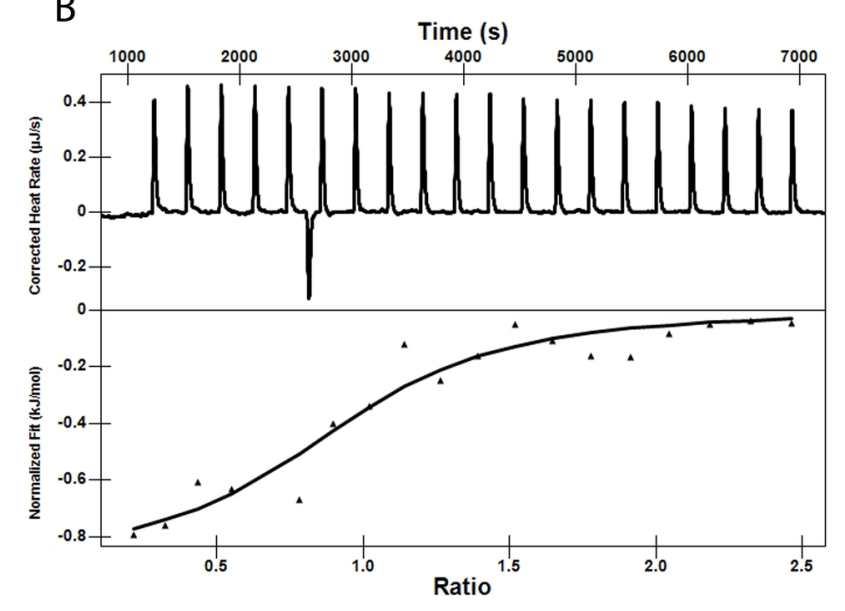

JMR_2718_F4.tif 


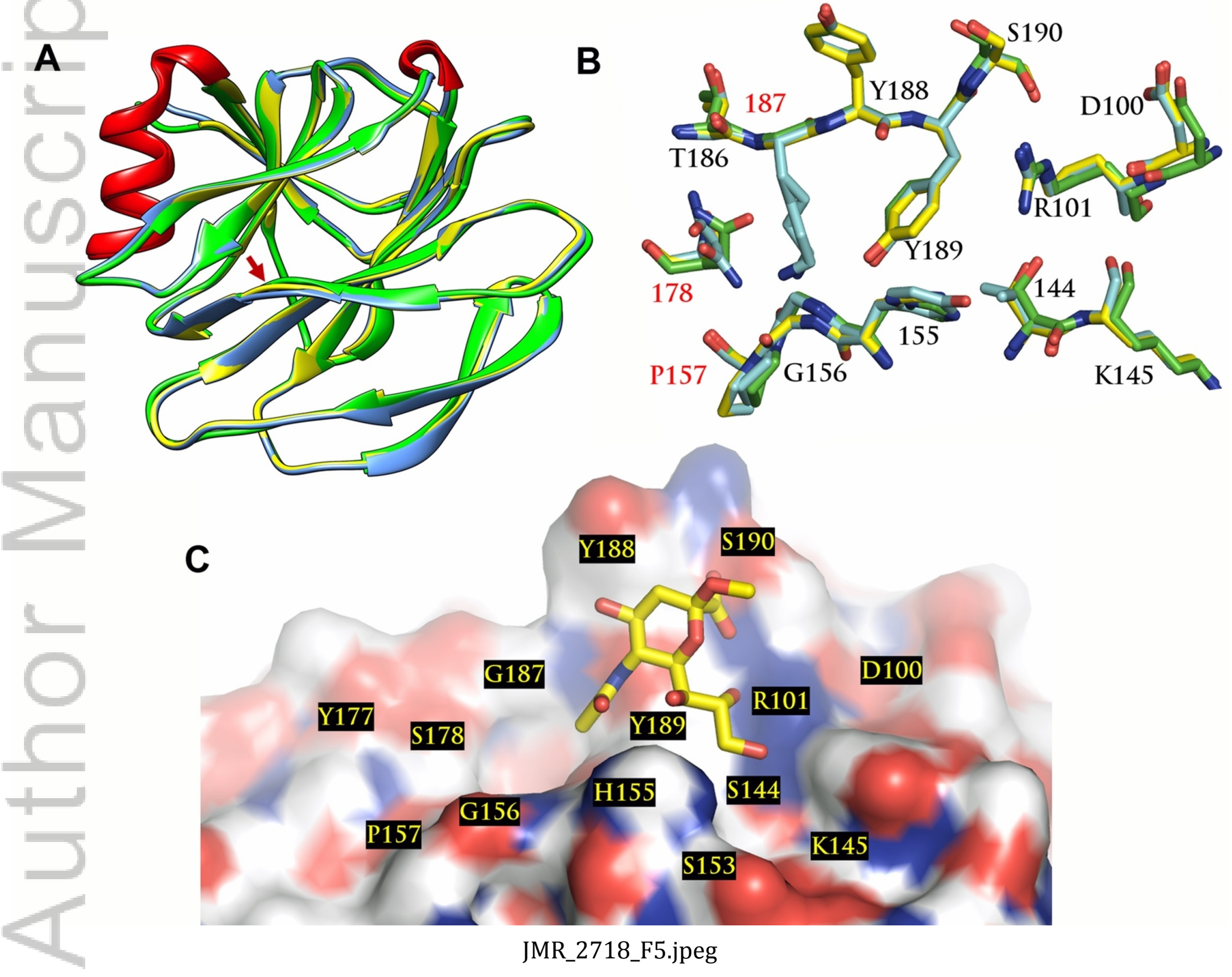

This article is protected by copyright. All rights reserved. 


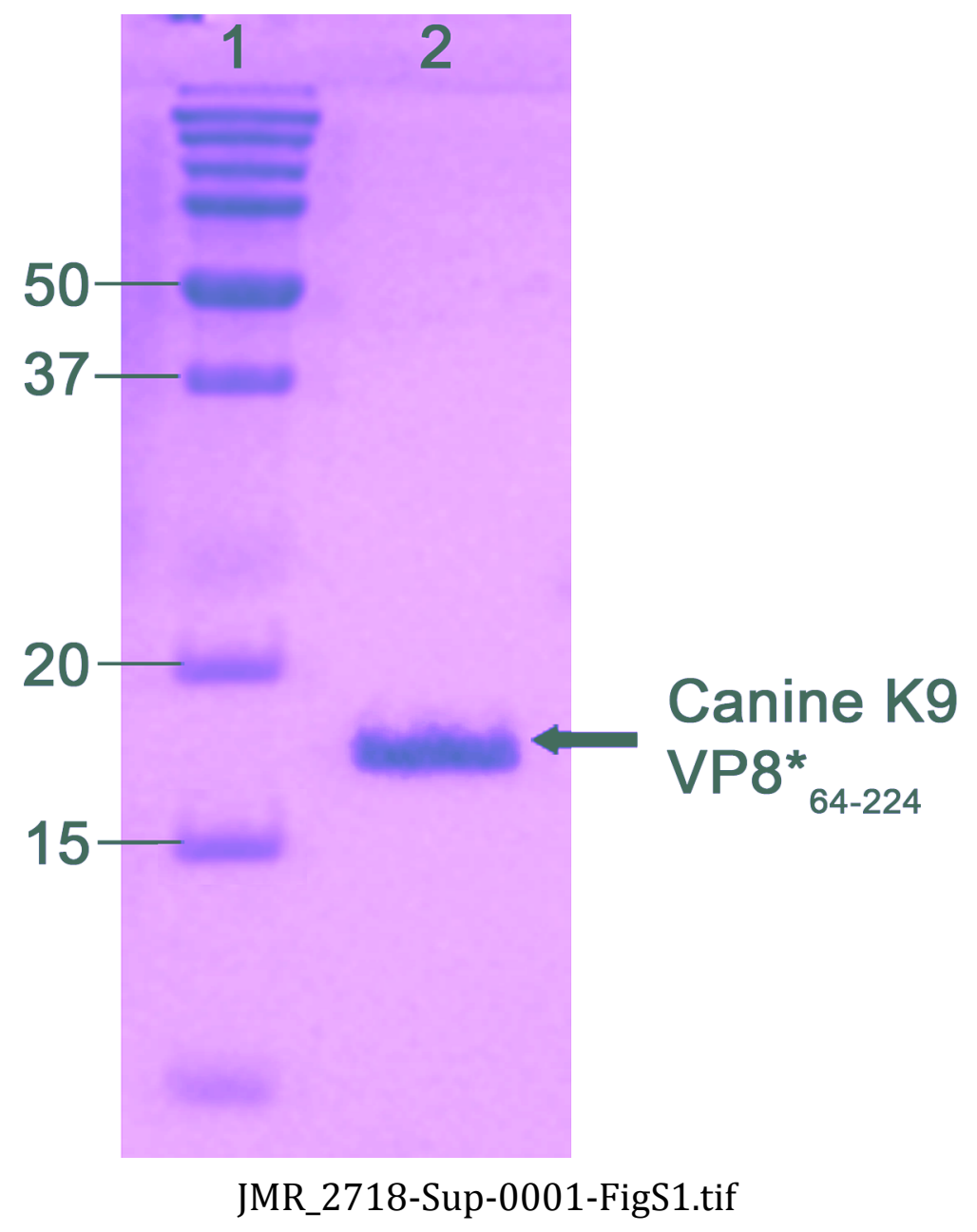

This article is protected by copyright. All rights reserved. 


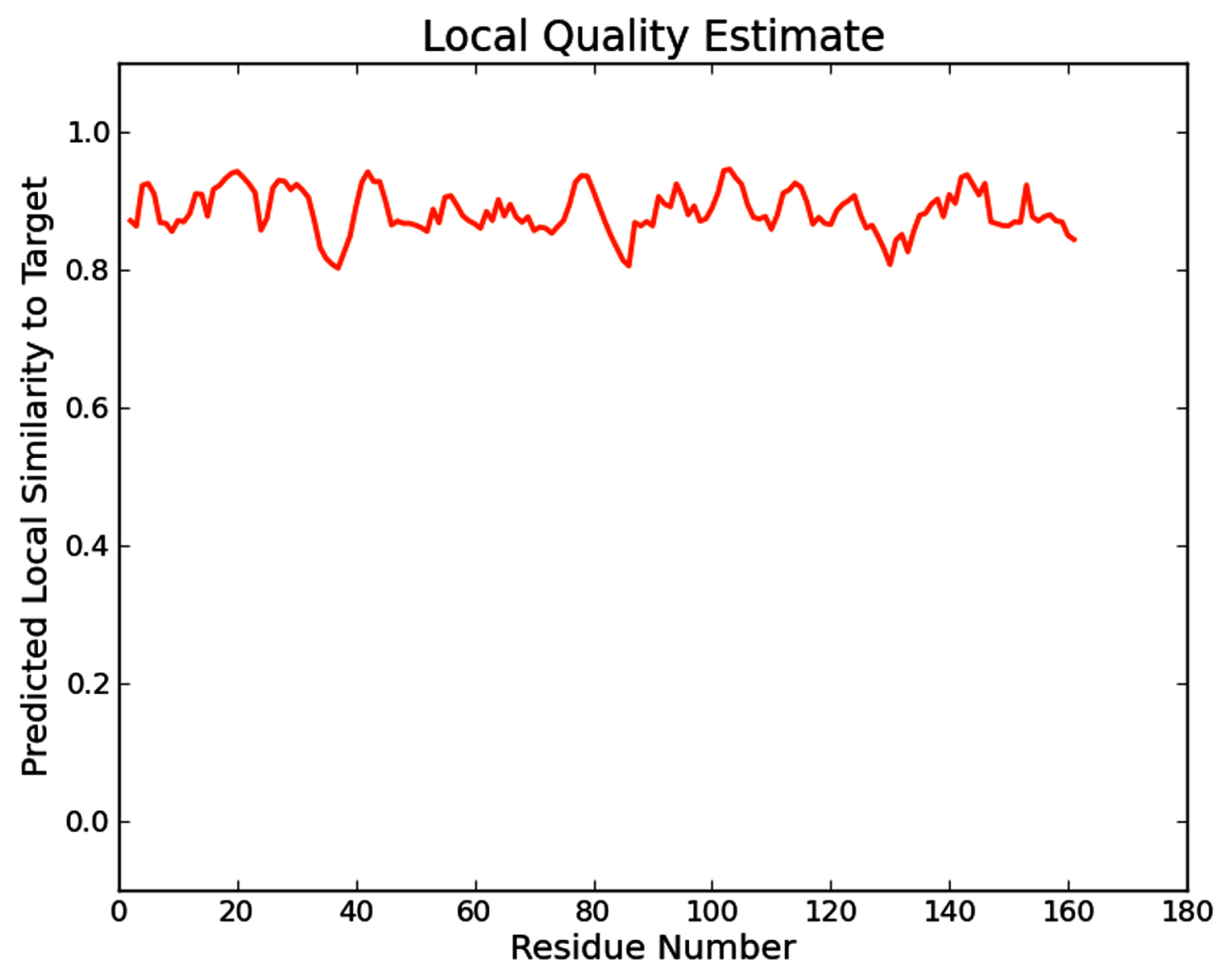

JMR_2718-Sup-0001-FigS2.tif 


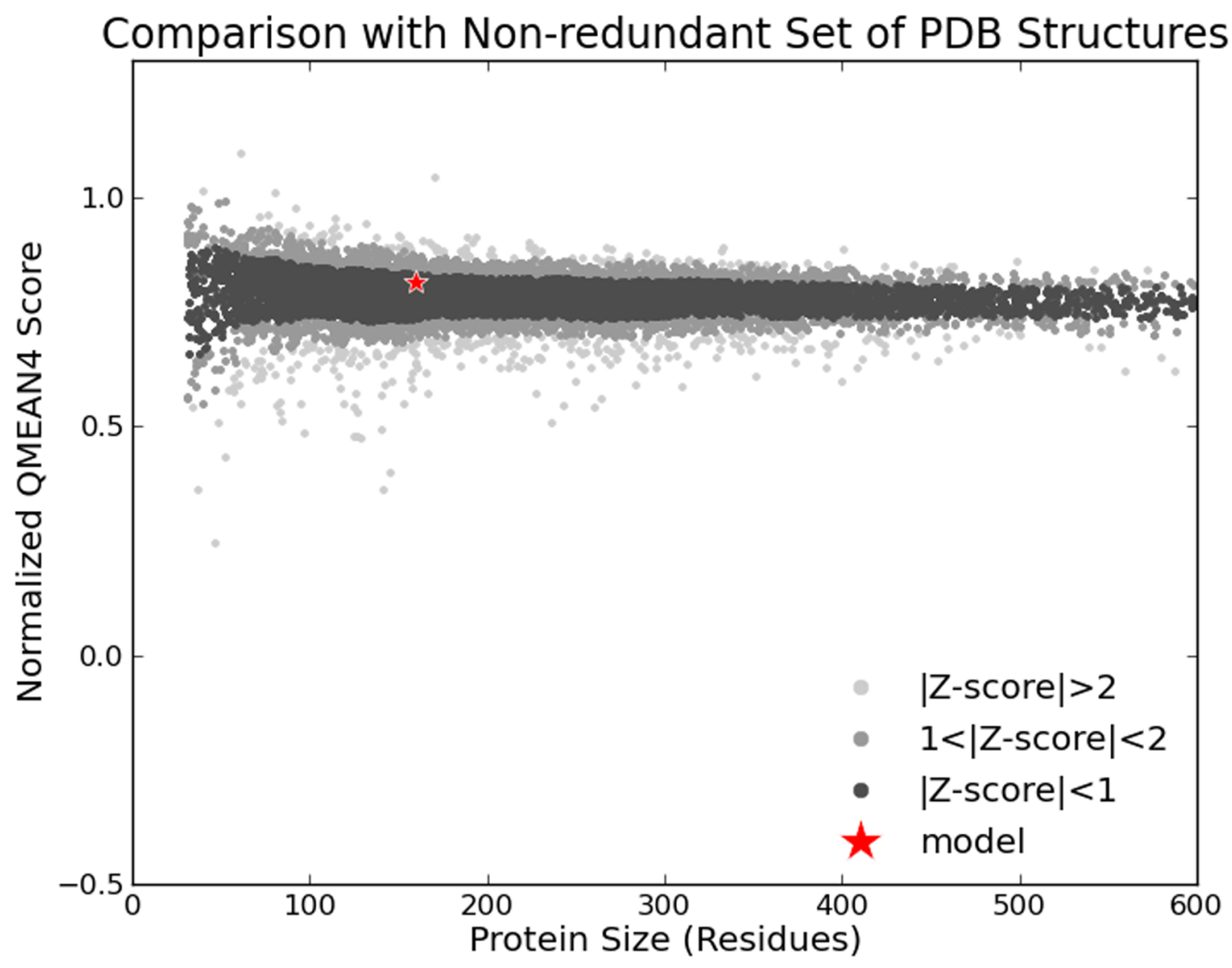

JMR_2718-Sup-0001-FigS3.tif 


\section{University Library}

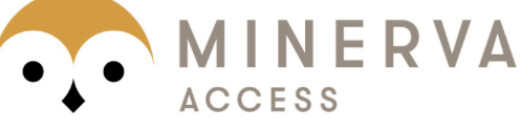

A gateway to Melbourne's research publications

Minerva Access is the Institutional Repository of The University of Melbourne

Author/s:

Mishra, R;Yu, X;Kishor, C;Holloway, G;Lau, K;von Itzstein, M;Coulson, BS;Blanchard, H

Title:

Specificity and affinity of neuraminic acid exhibited by canine rotavirus strain K9 carbohydrate-binding domain (VP8*)

Date:

2018-09-01

Citation:

Mishra, R., Yu, X., Kishor, C., Holloway, G., Lau, K., von Itzstein, M., Coulson, B. S. \& Blanchard, H. (2018). Specificity and affinity of neuraminic acid exhibited by canine rotavirus strain K9 carbohydrate-binding domain (VP8*). JOURNAL OF MOLECULAR RECOGNITION, 31 (9), https://doi.org/10.1002/jmr.2718.

Persistent Link:

http://hdl.handle.net/11343/283900 